\title{
Proposing an Improved Risk Assessment Model: A Case Study in Saba Tower
}

\author{
Mehraneh Davari, Siamak Haji Yakhchali, and Sirous Shojaie
}

\begin{abstract}
Effectively managing risk is an essential element of successful project risk management. In this paper, we propose a novel risk assessment technique which uses failure mode and effects analysis (FMEA) method based on ELENA's risk management model. ELENA's project management model incorporates the knowledge of project management provided by the PMBOK and the PRINCE2 methodologies to propose a model that covers both the knowledge of project management and the guidelines about how to use such this knowledge. The process described for managing risk in ELENA is identical to that in AS/NZS ISO 31000:2009. Risk assessment in PMBOK is the result of combining risks probability and impact, whereas present study proposes a new risk assessment model build on FMEA. FMEA analyzes risks through risk priority number (RPN) which contains three parameters including Detection (D), Occurrence (O) and Severity (S). Then, we assigned a threshold value equal to 125 to classify failures or required corrective actions. The purpose of this paper is to improves the accuracy of the assessment and optimize the decision making process in organizations. Finally, a case study of the Saba tower is presented.
\end{abstract}

Keywords-Failure mode and effect analysis (FMEA), Risk management, Risk assessment, Risk-Priority-Number (RPN).

\section{INTRODUCTION}

Today effectively managing risk is an essential part of successful project risk management. Proper risk management can assist the project manager to mitigate against both known and unanticipated risks on projects. Failure to perform effective risk management can cause many problems for its stakeholders. So, being aware of generic risks and seek for potential risks which may occur in future force organizations prepare plans to identify risks and employ different tools to control them. In this regard, various standards, methodologies and models have been proposed to determine the priority of projects' risks. The PMBOK was created by the PMI (Project Management Institute), to ensure a set of knowledge principles in project management. The purpose is to guide a project manager to fulfil successfully a project [3]. The PRINCE2 is the other risk management methodologies which was created in 1989 by CCTA (the Central Computer and Telecommunications Agency). It is a method of project

Mehraneh Davari, International Campus / Amirkabir University of Technology (Tehran Polytechnic)Iran mdavari@aut.ac.ir

Siamak Haji Yakhchali, School of Industrial Engineering / College of Engineering, University of Tehran Iran yakhchali@ut.ac.ir

Sirous Shojaie, School of Industrial Engineering / College of Engineering, Iran University of Science \& Technology Iran shojaees@yahoo.com management structured based on experience gained in thousands of projects and contributions of numerous sponsors, managers, project teams, academics, trainers and consultants. ELENA's process described for risk management is identical to that in AS/NZS ISO 31000:2009. ELENA's model for project management incorporates the knowledge of project management provided by PMBOK and PRINCE2 methodology to create a model which keeps the advantages of previous models in addition to improve their function. Performing risk analysis in PMBOK is the process of prioritizing risks by assessing and combining their probability of occurrence and impact, whereas in this paper we utilize FMEA method for ELENA's risk assessment to be precisely evaluated in comparison to PMBOK. Failure Mode and Effects Analysis (FMEA) is an effective problem prevention methodology which can easily interface with many engineering and reliability methods [1]. It determines the risk priorities of failure modes in an organization through the risk priority number (RPN) value. RPN is calculating through multiplication of the occurrence (O), severity (S) and detection (D) of a potential failure [2]. So, proposed model can have a high potential to identify more risks and improve the safety. The paper is organized as follows. In Section II, a literature review of management methodologies and an introduction of FMEA technique and its advantages is provided. Section III introduces a novel model which utilizes FMEA method for risk assessment to be analyzed precisely. In Section IV, an example is provided and a study is carried out for Saba tower. Finally, the paper is concluded in Section V with a brief summary on topics for future research.

\section{II.LITERATURE REVIEW}

There is now an extensive professional literature providing guidelines and frameworks for best practice in project management. In this section a brief review of them will be provided.

\section{A. Introduction to PMBOK}

"The PMBOK was created by the PMI (Project Management Institute), to ensure a set of knowledge principles in project management. The PMBOK is a detailed framework of nine knowledge areas, broken down into activities across five stages or process groups of the project life cycle, that are claimed to encompass the sum of knowledge generally recognized as good practice in the project management 
profession" [4]. According to PMBOK [3] project risk management includes the processes of conducting risk management planning, identification, analysis, response planning, and controlling risk on a project. The objectives of project risk management are to increase the likelihood and impact of positive events, and decrease the likelihood and impact of negative events in the project [3].

\section{B. Introduction to PRINCE2}

"PRINCE2, Projects in Controlled Environments, was created in 1989 by CCTA, since then called by OGC (the Office of Government Commerce). It is a method of project management structured based on experience gained in thousands of projects and contributions of numerous sponsors, managers, project teams, academics, trainers and consultants. The latest version of this methodology tries to approach a generic approach to become flexible to the point of shaping all types of design" [4].

The PMBOK is a descriptive methodology that introduces tools and techniques for project management and the sequence used for process execution, while the PRINCE2 provides guidelines about how the techniques of project management should be structured and implemented. So, both the PMBOK and the PRINCE2 methodologies are compatible if used appropriately [4].

\section{Introduction to ELENA}

ELENA's project guideline is a structured approach for project management that can manage all levels of organization (project, program and portfolio) effectively. This native Iranian model describes the principles, concepts, processes and tools required for project management along with their utilization method in projects with different characteristics. The process described for managing risk in ELENA is identical to that in AS/NZS ISO 31000:2009. ELENA's project management model integrates both PMBOK and PRINCE2 methodologies to keep their advantages in addition to improve each methodology.

Compared to the mentioned methodologies, ELENA has many other noticeable merits such as:

1) ELENA's guideline proposes a project methodology with required tools which has not yet been introduced in this area.

2) ELENA's guideline has been able to provide a method for the integrated management of risks, incidents, changes, and exceptions with different perspective to risk, incident, change and exception.

3) ELENA's guideline has been designed and developed at four levels including people, project, program and D. Introduction to FMEA

"A Historically FMEA was in use by NASA as early as 1963 but became better known when implemented by the Ford car manufacturers in about 1977" [1]. "A FMEA is a systematic method for identifying failure modes of system, process, design, service and machinery. FMEA is widely used by corporations, manufacturing organizations and firms to portfolio which is the first time that a guideline considers 4 project levels in an organization in integrated manner.

4) ELENA's guideline is the result of practical experience and the use of best practices. Experience of deploying and managing various management systems in organizations like PRINCE2 and PMBOK revealed some weakness which were not possible to modify their structures. All these corrections have been collected as the best practices in the ELENA's project guideline. So, ELENA's guideline is the result of the best practices of deploying project and operation management systems.

5) Despite the fact that ELENA's guideline is an Islamic management model of Iran, it has been developed with a global perspective based on a different international basis, which is unique in its own kind.

TABLE I makes a comparison between ELENA's project management model and well-known project management models.

TABLE I

COMPARISON OF ELENA'S PROJECT MANAGEMENT MODEL WITH WORLDWIDE PROJECT MANAGEMENT MODELS

\begin{tabular}{|c|c|c|c|}
\hline Attribute & PRINCE2 & PMBOK & ELENA \\
\hline Body of knowledge & & $\sqrt{ }$ & $\sqrt{ }$ \\
\hline Methodology & $\sqrt{ }$ & $\sqrt{ }$ \\
\hline $\begin{array}{c}\text { Comprehensive and unified } \\
\text { documentation }\end{array}$ & & $\sqrt{ }$ & $\sqrt{ }$ \\
\hline Varied practical criteria & & $\sqrt{ }$ & $\sqrt{ }$ \\
\hline Customization Capability & $\sqrt{ }$ & $\sqrt{ }$ \\
\hline $\begin{array}{c}\text { Knowledge of design and } \\
\text { portfolio management }\end{array}$ & $\sqrt{ }$ & $\sqrt{ }$ \\
\hline $\begin{array}{c}\text { Compliance and coordination } \\
\text { with design and portfolio } \\
\text { management }\end{array}$ & & & $\sqrt{ }$ \\
\hline $\begin{array}{c}\text { Availability of the developer } \\
\text { group }\end{array}$ & & & \\
\hline $\begin{array}{c}\text { Compliance with the } \\
\text { conditions of Iran's projects }\end{array}$ & & & \\
\hline
\end{tabular}

There are some studies that use ELENA. Nikkhou, Taghizadeh, and Hajiyakhchali [5] proposed a five-level portfolio management maturity model called ELENA which is based on the structural portfolio management of ELENA guidance approach. This model includes all the necessary concepts, processes and documentations for the portfolio management. Another study by Shojaie et al. [6] proposed ELENA's project management maturity model as the newest project management maturity model which has yet been introduced. It has 5 levels for maturity assessment and provides both continues and discrete assessment results. It was implemented in one of the biggest Iranian construction and industrial companies.

evaluate the effects of the failure modes. The goal of FMEA is to determine the reasons of the failure modes; after that seeks for ways to reduce or eliminate the chance of failure" [2].

"In the FMEA approach, failures can be equally treated as risks, and they are prioritized according to how serious (S) the consequences thereof are, how frequently they occur (O), and how easily they can be detected (D). This tool combines the 
knowledge and experience of people to identify the potential failure modes of a product or process, rank priority for attention according to the respective consequences of the failures, and eliminate the chance of potential failures occurring. The main idea is to generate an RPN for each failure mode" [7]. RPN is the multiplication of Severity (S), Occurrence (O) and Detectability (D).

Risks which may have positive or negative effect, is an indispensable part of both PMBOK's and ELENA's model. According to TABLE I, despite the wide application of PMBOK in identifying projects' risks, it has some weakness. In this methodology the effect of risk is assessed through only two parameters in Probability and Impact Matrix technique which are occurrence (O) and severity (S). While, this paper precisely evaluated risks based on FMEA method. So, the main contribution of this paper is proposing a more detailed risk assessment model based on ELENA's risk management model. This model applies FMEA which determines risk priority based on risk priority number (RPN). RPN is the product of the three input parameters including occurrence (O), detectability (D) and severity (S). These results help analysts to identity failures and their causes. In this paper we assigned a complex specific RPN threshold value equal to 125 to classify failures. Corrective actions are required for the failures that are have a value greater than $125 \mathrm{RPN}$. Section III will explain this novel method elaborately. This value is determined by organizational strategies.

\section{PROPOSED MODEL}

Risk is measured through only two parameters named occurrence (O) and severity (S) in PMBOK methodology. So, in this paper risk is evaluated via three factors to make the assessment more detailed and cover previous researches weakness. This paper employs an elaborated risk analysis technique called FMEA based on ELENA's project risk management model. The proposed risk model is summarized in Fig. 1. A detailed description is as follows:

\section{A. Risk Management in ELENA}

Project Risk management process in ELENA is defined as the systematic processes of establishing the project risk policy, defining risk criteria, identifying risk, analyzing risk, planning risk, controlling risk and reviewing. Section B will present a novel elaborated risk analysis method based on FMEA for ELENA's project risk management model.

\section{B. Failure Mode and Effects Analysis (FMEA)}

FMEA is a proactive method that prevents system faults before they occur. Each failure mode will be assessed in three parameters, namely, severity (S), likelihood of occurrence (O), and difficulty of detection of the failure mode (D) [1]. The evaluation system numbers are between 1 and 10 for each of the three parameters as described in TABLE V - TABLE VI -

TABLE VII. The main idea is to generate a risk priority number (RPN) for each failure mode (see "((1)”).

$$
\text { RPN }=\text { Severity }(S) \times \text { Occurrence }(\mathrm{O}) \times \text { Detectability }(D)
$$

The failure modes with higher RPNs are assumed to be more important and will be given higher priorities for correction. The RPNs helps the decision making team to identify the parts or processes that need the priority actions for improvement or appropriate reaction [1]. In this research RPN threshold value is equal to 125 to classify failures which is determined by organizational strategies.

\section{Processes of the Proposed Model}

In this section procedures of new risk assessment model will be explained through ELENA's risk management processes (Fig. 1).

1)Determine the project risk policy.

2)Define risk criteria.

3)Identify risk.

4) Analyze risk using FMEA method (described as follows):

I. Collect the system function information.

II. Identify potential failures of product/process; this includes problems, concerns, and opportunity of improvement.

III. Identify consequence of failures to other components/next processes, operation, customers and government regulations.

IV. Identify the potential root cause of potential failures.

V. Detectability rating: likelihood of the process control to detect a specific root cause of a failure.

VI. Occurrence rating: estimation of the frequency for a potential cause of failures.

VII. Severity rating: rank the seriousness of the effect of the potential failures.

VIII. RPN calculation: product of the three inputs rating; severity, occurrence, and detectability.

IX. Specifying the high risk. RPN represents the overall risk of each failure.

$\mathrm{X}$. If $\mathrm{RPN} \leq 125$, then measures should be monitored and trends should be assessed. 1) If the trend is positive, then back to (3). 2) If the trend is negative, risk reduction in the term of corrective and preventive action should be done (It required to fill the corrective action form). Then if the corrective action is effective, go to (6). Otherwise, risk reduction in the term of corrective and preventive action should be done.

XI. If $R P N \geq 125$, risk reduction in the term of corrective and preventive action should be done. Then if the corrective action is effective, go to (6). Otherwise, risk reduction in the term of corrective and preventive action should be done (It required to fill the corrective action form).

5) Plan risk considering planning criteria.

6) Control risk and review. This is the final step and the measures reports are available. 


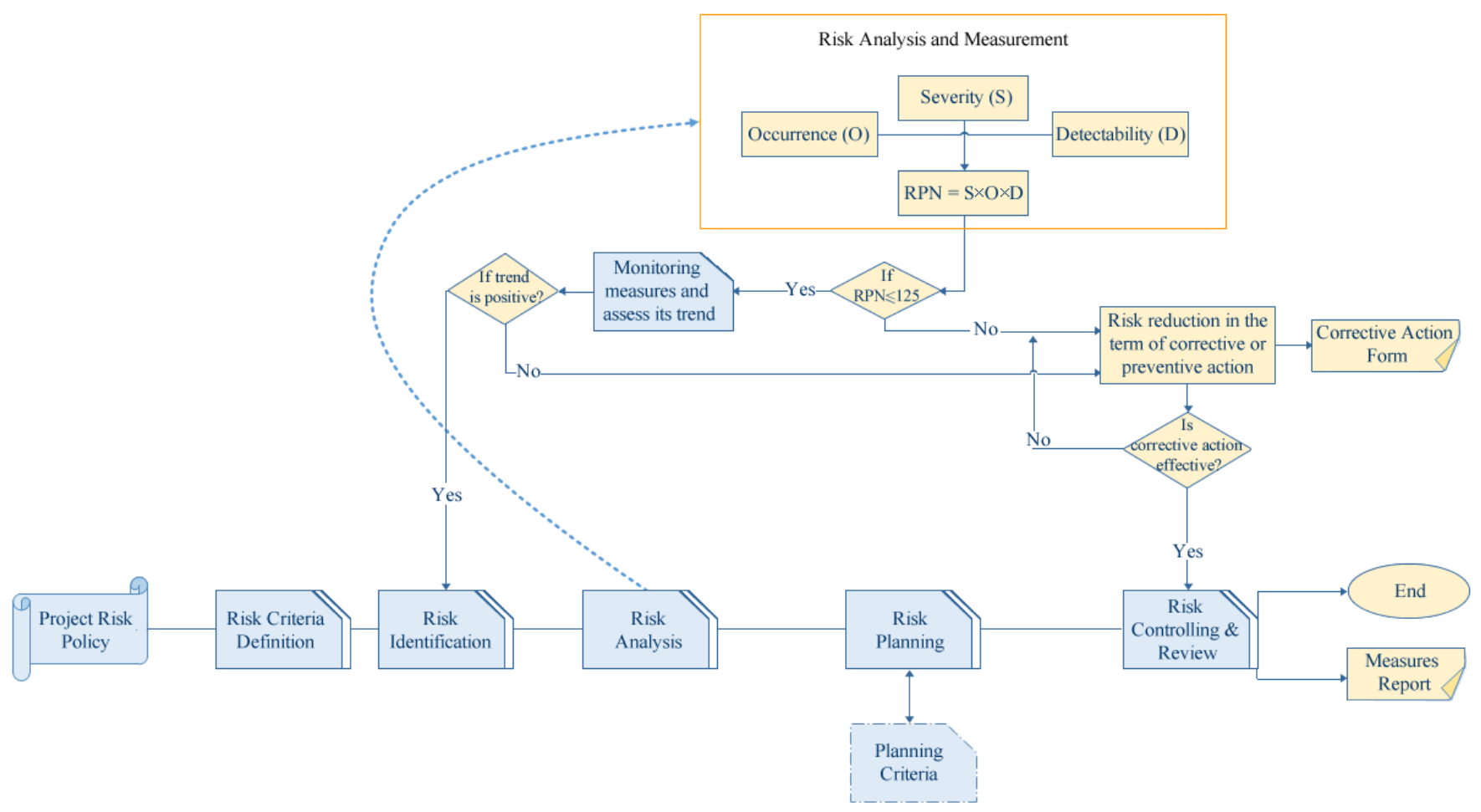

Fig. 1: Proposed risk assessment model based on ELENA's risk management model

\section{CASE Study}

The Case study in a 132 story tower located in region 22 of Cheetgar named Saba tower is investigated. In this section, risk is measured based on different stakeholders' opinion including project manager and PMO manager. Members are assigned scores to detectability, occurrence and severity parameters (from 1 to 10 provided in TABLE V - TABLE VI -

TABLE VII) according to the real situations. TABLE II provides a list of identified risk in Saba tower, then risks are assessed based on proposed FMEA model explained in section III.

In our risk analysis study, calculated RPN numbers are compared to 125 as a baseline, then high priority risks are identified. TABLE IV displays high priority risks which require corrective or preventive actions as a risk response.

TABLE II

MEASURING RPN BASED ON FMEA

\begin{tabular}{|c|c|c|c|c|c|}
\hline MEASURING RPN BASED ON FMEA & & \\
\hline $\mathbf{W}$ & Identified Risk & & & & \\
$\mathbf{S}$ & Poor planning system & 4 & 8 & 8 & 256 \\
\hline 1 & $\begin{array}{c}\text { RPN } \\
\text { scope }\end{array}$ & 3 & 6 & 6 & 108 \\
\hline 1 & $\begin{array}{c}\text { Client's failure in identification of project } \\
(\mathbf{D} * \mathbf{O} \\
* \mathbf{S})\end{array}$ \\
\hline 2 & Low human resource performance & 5 & 7 & 8 & 320 \\
\hline 1 & Unqualified subcontractors & 5 & 6 & 6 & 180 \\
\hline 4 & Project finance disruptions & 6 & 8 & 9 & 432 \\
\hline 4 & Economic inflations and price growth & 3 & 9 & 9 & 243 \\
\hline 1 & Incorrect project budget estimation & 2 & 7 & 8 & 112 \\
\hline 5 & Incompatibility of procurement with & 5 & 7 & 6 & 210 \\
\hline 4 & engineering design & 5 & 6 & 7 & 210 \\
\hline
\end{tabular}

\begin{tabular}{|c|c|c|c|c|c|}
\hline 8 & $\begin{array}{c}\text { Unfamiliarity of building codes and safety } \\
\text { regulations }\end{array}$ & 2 & 5 & 5 & 50 \\
\hline 7 & $\begin{array}{c}\text { Incompatibility of structure design with } \\
\text { architectural design }\end{array}$ & 4 & 7 & 6 & 168 \\
\hline 7 & $\begin{array}{c}\text { Incompatibility of building services } \\
\text { design with architectural design }\end{array}$ & 4 & 7 & 5 & 140 \\
\hline
\end{tabular}

TABLE III

PROJECT WORK OF PACKAGES BASED ON WBS

\begin{tabular}{|c|c|}
\hline Work of Packages & Description \\
\hline WBS 1 & Contract and land acquisition \\
\hline WBS 2 & Equipping workshop \\
\hline WBS 3 & Excavation \\
\hline WBS 4 & Foundation work \\
\hline WBS 5 & Manufacturing of steel structure \\
\hline WBS 6 & Erection of steel structure \\
\hline WBS 7 & Retaining walls work \\
\hline WBS 8 & Finishes work work \\
\hline WBS 9 & Mechanical equipment \\
\hline WBS 10 & Electrical equipment \\
\hline WBS 11 & Facade \\
\hline WBS 12 &
\end{tabular}

TABLE IV

RISK RESPONSE ACCORDING TO RISK PRIORITY

\begin{tabular}{|c|c|}
\hline Identified Risk & Risk Response \\
\hline Poor planning system & $\begin{array}{c}\text { Recruitment of project planning and } \\
\text { cost control experts }\end{array}$ \\
\hline Low human resource performance & $\begin{array}{c}\text { Precise position description } \\
\text { competencies }\end{array}$ \\
\hline Unqualified subcontractors & $\begin{array}{c}\text { Precise definition of equipment's } \\
\text { specifications }\end{array}$ \\
\hline Project finance disruptions & Forecasting prices increase \\
\hline $\begin{array}{c}\text { Economic inflations and price } \\
\text { growth }\end{array}$ & $\begin{array}{c}\text { Considering different finances } \\
\text { options }\end{array}$ \\
\hline Incompatibility of procurement & Precise estimation of quantity of \\
\hline
\end{tabular}




\begin{tabular}{|c|c|}
\hline with engineering design & materials \\
\hline Incorrect engineering design & $\begin{array}{c}\text { Budget determination after } \\
\text { approving design drawings }\end{array}$ \\
\hline $\begin{array}{c}\text { Incompatibility of structure } \\
\text { design with architectural design }\end{array}$ & $\begin{array}{c}\text { Regular meetings between structure } \\
\text { engineers, building services } \\
\text { engineers and architects }\end{array}$ \\
\hline $\begin{array}{c}\text { Incompatibility of building } \\
\text { services design with architectural } \\
\text { design }\end{array}$ & $\begin{array}{c}\text { Regular meetings between structure } \\
\text { engineers, building services } \\
\text { engineers and architects }\end{array}$ \\
\hline
\end{tabular}

TABLE V

SCORING RISK IDENTIFY BY FMEA (SEVERITY)

\begin{tabular}{|c|c|c|}
\hline Effect & Severity of Effect & Ran \\
king
\end{tabular}

TABLE VI

SCORING RISK IDENTIFY BY FMEA (OCCURRENCE)

\begin{tabular}{|c|c|c|}
\hline $\begin{array}{c}\text { Probability of } \\
\text { Failure }\end{array}$ & Failure Probability & Ranking \\
\hline Very High & Definitely (100\%) it occurs & 10 \\
\hline Very High & $\begin{array}{c}\text { Most probably (more than 90\%) it } \\
\text { occurs }\end{array}$ & 9 \\
\hline High & Most probably (about 80\%) it occurs & 8 \\
\hline High & Probably (about 70\%) it occurs & 7 \\
\hline Moderate & Most likely (about 60\%) it occurs & 6 \\
\hline Moderate & Most likely (about 40\% to 50\%) it & 5 \\
\hline occurs & 4 \\
\hline Moderate & Most likely (about 30\%) it occurs & 3 \\
\hline Low & Less likely (less than 20\%) it occurs & 2 \\
\hline Rarely & Less likely (less than 10\%) it occurs & 2 \\
\hline
\end{tabular}

TABLE VII

SCORING RISK IDENTIFY BY FMEA (DETECTION)

\begin{tabular}{|c|c|c|}
\hline Effect & Severity of Effect & $\begin{array}{c}\text { Ran } \\
\text { king }\end{array}$ \\
\hline Definitely & $\begin{array}{c}\text { In the meantime, there is no approach/mechanism } \\
\text { of the processes to identify the risk and to prevent } \\
\text { from occurring. }\end{array}$ & 10 \\
\hline Very High & $\begin{array}{c}\text { Very negligible chance (about 10\%) the system } \\
\text { methods can identify risk and prevent from } \\
\text { occurring. }\end{array}$ & 9 \\
\hline High & $\begin{array}{c}\text { Negligible chance (about 20\%) the system } \\
\text { methods can identify risk and prevent from } \\
\text { occurring. }\end{array}$ & 8 \\
\hline Moderate & $\begin{array}{c}\text { Very low chance (about 30\%) the system methods } \\
\text { can identify risk and prevent from occurring. }\end{array}$ & 7 \\
\hline Moderate & $\begin{array}{c}\text { Low chance (about 40\%) the system methods can } \\
\text { identify risk and prevent from occurring. }\end{array}$ & 6 \\
\hline Low & $\begin{array}{c}\text { Moderate chance (about 50\% to 60\%) the system } \\
\text { methods can identify risk and prevent from } \\
\text { occurring. }\end{array}$ & 5 \\
\hline Very Low & $\begin{array}{c}\text { Moderate chance (about 70\%) the system methods } \\
\text { can identify risk and prevent from occurring. }\end{array}$ & 4 \\
\hline Rarely & $\begin{array}{c}\text { High chance (about 80\%) the system methods can } \\
\text { identify risk and prevent from occurring. }\end{array}$ & 3 \\
\hline $\begin{array}{c}\text { Very } \\
\text { Rarely }\end{array}$ & $\begin{array}{c}\text { Very high chance (more than 90\%) the system } \\
\text { methods can identify risk/ prevent from occurring. }\end{array}$ & 2 \\
\hline $\begin{array}{c}\text { Complete } \\
\text { Uncertainty }\end{array}$ & $\begin{array}{c}\text { Procedures and procedures can identify risk and } \\
\text { prevent from occurring. }\end{array}$ & 1 \\
\hline
\end{tabular}

\section{V.CONCLUSION}

In this paper, a novel approach for measuring project risk is introduced in an attempt to overcome the shortcomings of the risk assessments in available studies. In this paper, a more accurate risk assessment method is presented based on ELENA's risk management model. This paper precisely evaluated risks based on FMEA technique in which risks are measured through three parameters including detectability, occurrence and severity. Comparing with the PMBOK and the PRINCE2 methodologies, the advantages of the ELENA are 1) being a body of knowledge and a methodology simultaneously, 2) having comprehensive and unified documentation, 3) compliance with the conditions of Iran's projects. Finally, performance of this novel risk assessment has been evaluated with a real case study in Saba tower.

\section{REFERENCES}

[1] S. K. Oraee, A. Yazdani-Chamzini, and M. H. Basiri, "Evaluting underground mining hazards by fuzzy FMEA," SME Annual Meeting, Feb. 27-Mar. 02, 2011, Denver, CO.

[2] H. Safari, Z. Faraji, and S. Majidian, "Identifying and evaluating enterprise architecture risks using FMEA and fuzzy VIKOR," Intell Manuf, 2016, pp. 475-486.

[3] A Guide to the Project Management Body of Knowledge, PMBOK Guide, Fifth Edition, 2013.

[4] S. Matosa, and E. Lopesa, "Prince2 or PMBOK - a question of choice," Procedia Technology 9, 2013, pp. 787-794.

[5] Sh. Nikkhou, K. Taghizadeh, and S. Hajiyakhchali, "Designing a Portfolio management maturity model (Elena)," Procedia - Social and Behavioral Sciences, 2016, pp. 318-325.

[6] S. Shojaei, S. Nouri, S. Haji Yakhchali, and Y. Rahimi, "Project Management Maturity Assessment with a new Elena Project management Maturity Model: a case study of Saba tower," in 11th International Project Management Conference, 2016. 
7th International Conference on Innovations in Engineering and Technology (ICIET-2017) Oct. 5-6, 2017 Paris (France)

[7] J. Yu, and S. Lee, "A Conflict-Risk Assessment Model for Urban Regeneration Projects Using Fuzzy-FMEA," KSCE Journal of Civil Engineering, Vo. 16, 2012, pp.1093-1103. 